\title{
Effects of fasting in Ramadan on Tropical Asiatic Moslems
}

\author{
By R. HUSAIN, M. T. DUNCAN*, S. H. CHEAH AND S. L. CH'NG \\ Faculty of Medicine, University of Malaya, 59100 Kuala Lumpur, Malaysia
}

(Received 29 November 1986 - Accepted 16 February 1987)

1. Anthropometric variables, resting heart rate and respiratory gas exchange were measured in twelve male and nine female Asiatic adult Moslems during the month of Ramadan, the week before and the month after Ramadan.

2. Energy intakes were estimated from dietary recall during fasting and non-fasting conditions.

3. Both male and female subjects experienced a decrease in body mass with the reduction in energy intake during fasting. Males experienced a greater reduction than females in resting heart rate; females lost more bodyweight and subcutaneous fat than males.

4. Urine output and fluid intake were measured in twelve male subjects for $1 \mathrm{~d}$ during each week of fasting and I d during the pre-fasting control period. Among the subjects examined, the Ramadan regimen did not result in changes in the pattern of fluid exchange.

Residents of Malaysia include Moslems who practise abstention from food and drink between dawn and sunset during the month of Ramadan. Preliminary studies on Moslems in Sudan have examined the effects of fasting on serum triglyceride and uric acid levels (Gumaa et al. 1978) and body-fluid balance (Mustafa et al. 1978). However, the biological effects of changes in activity and feeding patterns during the fasting month of Ramadan on Asiatic Moslems in Malaysia have not been studied. The present investigation examines changes in anthropometric and physiological variables which may be associated with the fasting month.

Twelve males and nine females volunteered for the study. A representative $24 \mathrm{~h}$ activity pattern for the subjects (Fig. 1) during the non-fasting months consists of $15 \mathrm{~h}$ of wakefulness (06.30-21.30 hours) and $9 \mathrm{~h}$ of sleep (21.30-06.30 hours) with four or five meals consumed at $3-4 \mathrm{~h}$ intervals (between 0.700 and 19.00 hours). In contrast, the general pattern during the fasting month consists of $20 \mathrm{~h}$ of wakefulness $(04.00-24.00$ hours $), 4 \mathrm{~h}$ of sleep, a $14.5 \mathrm{~h}$ fasting period with complete fluid and energy deprivation (05.00-19.30 hours), and three sessions of refeeding and rehydration at approximately $5 \mathrm{~h}$ intervals occurring at night between 19.30 and 04.00 hours.

Therefore, the month of Ramadan is associated with a prolonged period of fluid and energy deprivation during the day and a reduction in sleeping time. The 28-d fasting situation is also accompanied by heightened religious dedication which may result in an altered mental state which may affect physiological function.

\section{METHODS}

Studies were made on healthy adults (aged 20-45 years) engaged in indoor sedentary occupations who observed fasting during the month of Ramadan. The subjects gave their informed consent to the experimental procedures of the investigation.

They reported to the laboratory for anthropometric and cardiorespiratory measurements at the same time of day (between 09.00 and 11.00 hours) according to the following schedule: once during the week before Ramadan (pre-fasting control), once during the 5th week after Ramadan (post-fasting control) and twice during each week of fasting. Representative waking and feeding schedules are as presented in Fig. 1. The average of biweekly

\footnotetext{
* For reprints.
} 

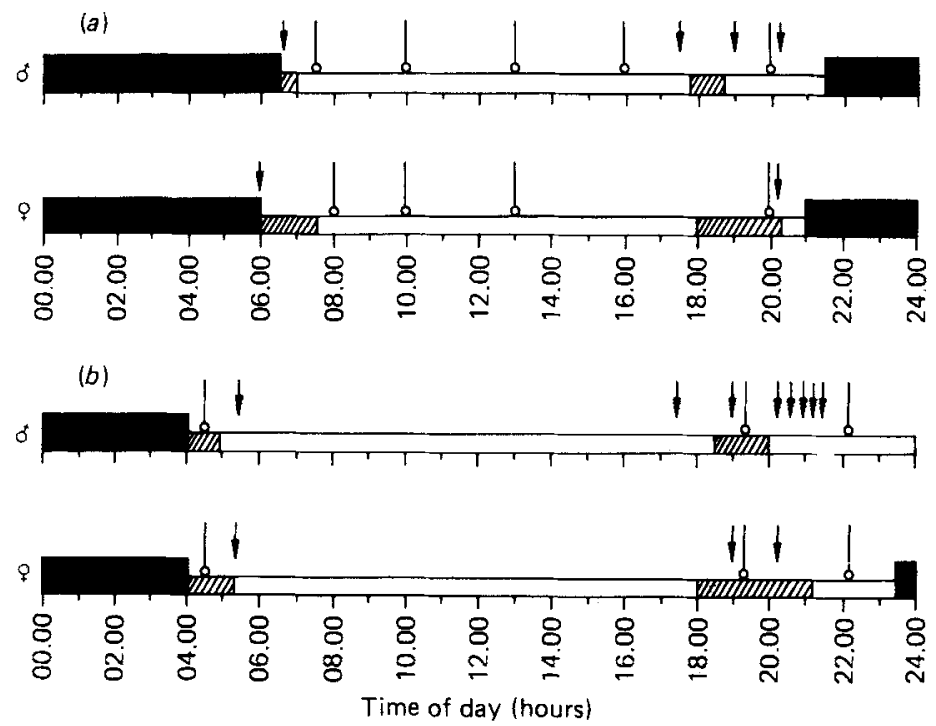

Fig. 1. Representative daily activity patterns during the (a) non-fasting (Pre-Ramadan) period and $(b)$ fasting (Ramadan) period for male and female subjects. (D) Sleep; () performance of household chores; $(\downarrow)$ feeding activity; $(\downarrow)$ praying activity.

measurements were taken to represent values for the week. The subjects rested in the laboratory for 20-30 min at an ambient temperature of $24^{\circ}$ before data collection began.

Body-weight was measured to the nearest $0.1 \mathrm{~kg}$. Skinfold thickness was measured to the nearest $1 \mathrm{~mm}$ with a Harpenden caliper. Readings made at four sites, i.e. at the subscapular fold, triceps, suprailiac and the calf areas, were summated as total skinfold. The maximum muscle girth at the biceps and calf was measured to the nearest $1 \mathrm{~mm}$ and summated. These measurements were made on the right side of the body according to the recommendations of Parnell (1954).

Oxygen uptake $\left(\dot{V}_{\mathrm{O}_{2}}\right)$ and carbon dioxide elimination $\left(\dot{V}_{\mathrm{CO}_{2}}\right)$ were measured by the opencircuit method using the standard Douglas Bag technique (Consolazio et al. 1963). Expired air was collected for $10 \mathrm{~min}$ with the subject at rest. Portions of expired air were analysed for $\mathrm{O}_{2}$ and $\mathrm{CO}_{2}$ content with the Lloyd Gas Analyser (A. Gallenkamp \& Co. Ltd, Loughborough, Leics). $\dot{V}_{\mathrm{O}_{2}}, \dot{V}_{\mathrm{CO}_{2}}$ and respiratory exchange ratio (RER) were calculated according to standard formulas (Consolazio et al. 1963). Heart rate was measured by radial pulse palpation.

Mean values during each week of fasting were compared with those from the pre-fasting control period by use of a paired $t$ test. Statistical significance was accepted at $P<0 \cdot 10$ and $P<0.05$.

All the subjects kept daily records of activity patterns and dietary fluid and food intakes during the experimental period. Standard procedures for record-keeping were explained to the volunteers who were all literate and had undergone between 6 and 18 years of formal education. The records were reviewed by interview as they were submitted.

The male subjects collected total $24 \mathrm{~h}$ urine output once during each week of fasting as well as once during the pre-fasting and the post-fasting control periods. Estimations of daily fluid intake were derived from the records submitted and corresponded with the period of urine collection. 
Analysis of energy intakes and activity patterns were performed for each Wednesday and Friday during a pre-fasting control week and during each week of fasting. The days selected for analysis were mid-week working days when the subjects were more likely to adhere to a similar routine with minimum variability.

Food diary entries made by the subjects were expressed as portions consumed in terms of household measures. The subjects were guided by a demonstration of standard household measures before the experimental period. These measures were then converted to weights in terms of edible portions and subsequently to the energy values of the items consumed from food tables provided by Hodder (1985). Information for the preparation of the tables (Hodder, 1985) was extracted mainly from Food Composition Table for Use in East Asia compiled by Food and Agriculture Organization (1972), and Composition of Foods Commonly used in Singapore compiled by the National University of Singapore (1983). The tables were based on local ethnic food preparation and feeding procedures applicable to the Malaysian subjects. The energy intakes were taken to reflect approximations of the average energy intake for non-fasting conditions and weeks $1-4$ of fasting.

Analysis of representative daily activity patterns consists of estimations of the total time spent in prayer and performing household chores away from the workplace (between 17.00 and 09.00 hours) during a pre-fasting control week and during each week of fasting. Observance of the Ramadan regimen was expected to have maximal impact on performance of these activities while the rest would remain relatively unaffected. Analysis of the type of housework performed justified the assumption that the work rate was light to moderate and approximately equivalent to an energy expenditure rate of $2.09 \mathrm{~kJ}(0.5 \mathrm{kcal}) / \mathrm{kg}$ bodyweight per $10 \mathrm{~min}$ based on tables provided by Hodder (1985).

\section{RESULTS}

Changes in anthropometric variables during the fasting month are presented in Table 1 . A decrease in body-weight was apparent by the 2 nd week with a greater decline in the females. The lower body-weights were maintained throughout the fasting month with a return to pre-fasting values when normal feeding patterns were re-established. Total skinfold thickness and total muscle girth showed similar changes although the trends were not statistically significant.

Resting heart rates were markedly lowered in the males during the month of Ramadan while responses in the females were only slightly decreased (Fig. 2, Table 2). $\mathrm{O}_{2}$ uptake declined in all the subjects compared with pre-fasting control levels. The decrease in $\dot{V}_{\mathrm{o}}$, reached statistical significance on two occasions (Fig. 2, Table 2). Means for resting RER were between 0.91 and 0.93 for both male and female subjects during the pre-fasting and post-fasting periods. During fasting, the females showed a decrease to 0.84 (SD 0.04) by week $1(P<0.1)$ which further declined to 0.82 during the subsequent weeks of fasting $(P<0.05)$ followed by a rapid return to 0.91 with restoration to normal conditions (Fig. 2). Resting RER showed a small and non-significant decline to approximately 0.89 in the males during fasting with a return to 0.93 after Ramadan.

Food intake for normal non-fasting conditions averaged 10.7 (SD 2.8) and 7.2 (SD 2.7) $\mathrm{MJ} / \mathrm{d}$ for the males and the females respectively. The average decreases in energy intake during the fasting month for weeks 14 were $23,25,22$ and $20 \%$ for males respectively, and 7, 14, 6 and $20 \%$ for females.

Findings presented in Table 3 indicate that the time utilized for praying activity was extended for all the subjects during the month of Ramadan with the male group spending more time on prayer relative to the female group during the fasting and non-fasting periods. The Ramadan regimen did not result in changes in time spent on performance of household 
Table 1. Anthropometric changes before, during and after fasting in Malaysian Moslems

(Values are means and standard deviations; percentage change represents change in means from pre-fast control in twelve males and nine females. Mean height, male $1.63 \mathrm{~m}$, female $1.54 \mathrm{~m}$, mean body surface area, male $1.68 \mathrm{~m}^{2}$ female $1.46 \mathrm{~m}^{2}$ )

\begin{tabular}{|c|c|c|c|c|c|c|c|c|}
\hline & \multicolumn{2}{|c|}{ Pre-fast control } & \multicolumn{2}{|c|}{ Post-fast control } & \multicolumn{4}{|c|}{ Week of fasting $(\%)$} \\
\hline & Mean & SD & Mean & SD & 1 & 2 & 3 & 4 \\
\hline \multicolumn{9}{|c|}{ Body-wt (kg) } \\
\hline $\begin{array}{l}0 \\
9\end{array}$ & $\begin{array}{l}62 \cdot 9 \\
49 \cdot 9\end{array}$ & $\begin{array}{l}5 \cdot 9 \\
6 \cdot 5\end{array}$ & $\begin{array}{l}62 \cdot 6 \\
49 \cdot 2\end{array}$ & $\begin{array}{l}6 \cdot 3 \\
6 \cdot 6\end{array}$ & $\begin{array}{l}-0.63 \\
-0.74\end{array}$ & $\begin{array}{l}-1 \cdot 43 \\
-2 \cdot 18\end{array}$ & $\begin{array}{l}-1.90 \\
-2.80\end{array}$ & $\begin{array}{l}-2.54 \\
-3.20\end{array}$ \\
\hline \multicolumn{9}{|c|}{ Total skinfold (mm) } \\
\hline $\begin{array}{l}0 \\
0 \\
0\end{array}$ & $\begin{array}{l}47 \\
57\end{array}$ & $\begin{array}{l}17 \cdot 3 \\
15 \cdot 3\end{array}$ & $\begin{array}{l}45 \\
54\end{array}$ & $\begin{array}{l}15 \cdot 7 \\
15 \cdot 3\end{array}$ & $\begin{array}{l}-2 \cdot 72 \\
-0 \cdot 70\end{array}$ & $\begin{array}{l}-5 \cdot 38 \\
-2 \cdot 22\end{array}$ & $\begin{array}{l}-4 \cdot 72 \\
-5.93\end{array}$ & $\begin{array}{l}-5 \cdot 74 \\
-8.00\end{array}$ \\
\hline \multicolumn{9}{|c|}{ Muscle girth (mm) } \\
\hline $\begin{array}{l}0 \\
9\end{array}$ & $\begin{array}{l}68 \\
61\end{array}$ & $\begin{array}{l}3 \cdot 1 \\
4 \cdot 8\end{array}$ & $\begin{array}{l}67 \\
59\end{array}$ & $\begin{array}{l}3 \cdot 2 \\
4 \cdot 9\end{array}$ & $\begin{array}{l}-0 \cdot 17 \\
-0 \cdot 37\end{array}$ & $\begin{array}{l}-0.40 \\
-0.90\end{array}$ & $\begin{array}{l}-0.59 \\
-1.83\end{array}$ & $\begin{array}{l}-1.24 \\
-2.39\end{array}$ \\
\hline
\end{tabular}
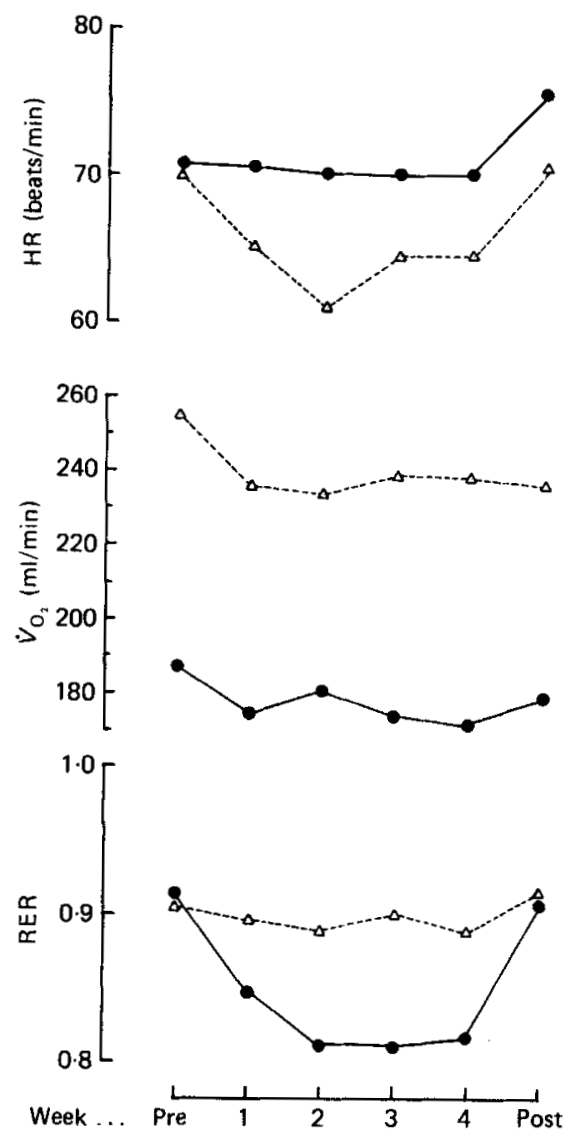

Fig. 2. Average heart rate (beats $/ \mathrm{min} ; \mathrm{HR})$, oxygen uptake $\left(\mathrm{ml} / \mathrm{min} ; \dot{V}_{\mathrm{o}_{\mathrm{g}}}\right)$ and respiratory exchange ratio (RER) during the pre-fasting control period (Pre) and post-fasting control period (Post) and weeks $1-4$ of fasting in males $(\triangle-\triangle)(n 12)$, and females $(-\infty)(n 9)$. 
Table 2. Physiological changes before, during and after fasting in Malaysian Moslems

(Values are means and standard deviations; percentage change represents change in means from pre-fast control in twelve males and nine females)

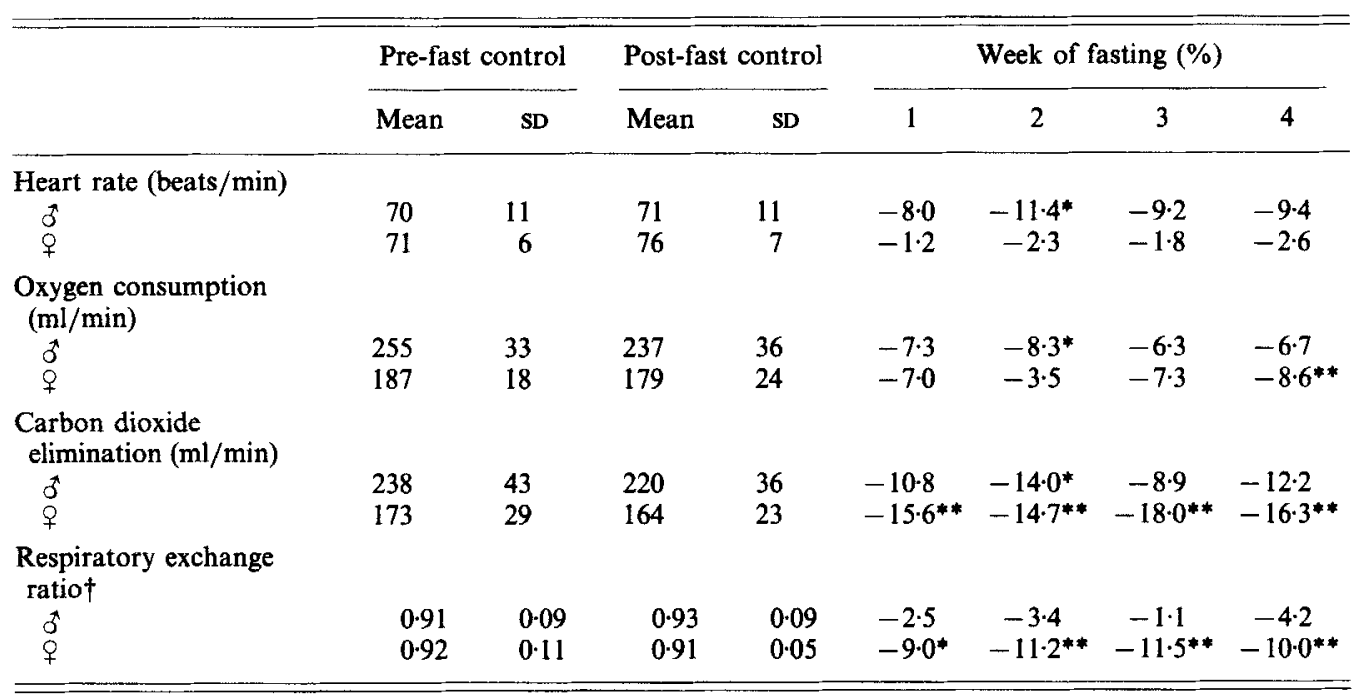

Mean values were significantly different from those for pre-fast control: ${ }^{*} P<0 \cdot 1,{ }^{* *} P<0.05$.

$\dagger$ Calculated according to Consolazio et al. (1963).

Table 3. Total time spent (min) on praying activity and performance of household chores by Malaysian Moslems in a representative day before and during the fasting month (Mean values with their standard errors, no. of subjects in parentheses)

\begin{tabular}{|c|c|c|c|c|c|c|c|c|c|c|}
\hline & \multirow{2}{*}{\multicolumn{2}{|c|}{$\begin{array}{l}\text { Pre-fast } \\
\text { control }\end{array}$}} & \multicolumn{8}{|c|}{ Week of fasting } \\
\hline & & & \multicolumn{2}{|c|}{1} & \multicolumn{2}{|c|}{2} & \multicolumn{2}{|c|}{3} & \multicolumn{2}{|c|}{4} \\
\hline & Mean & $\mathrm{SE}$ & Mean & SE & Mean & $\mathbf{S E}$ & Mean & SE & Mean & SE \\
\hline \multicolumn{11}{|l|}{ Praying } \\
\hline $\begin{array}{ll}0 & (12) \\
9 & (9)\end{array}$ & $\begin{array}{l}65 \\
15\end{array}$ & $\begin{array}{r}18 \\
5\end{array}$ & $\begin{array}{r}107 \\
60\end{array}$ & $\begin{array}{l}24 \\
18\end{array}$ & $\begin{array}{l}94 \\
60\end{array}$ & $\begin{array}{l}24 \\
11\end{array}$ & $\begin{array}{l}92 \\
60\end{array}$ & $\begin{array}{l}24 \\
14\end{array}$ & $\begin{array}{l}92 \\
45\end{array}$ & $\begin{array}{r}25 \\
9\end{array}$ \\
\hline \multicolumn{11}{|c|}{ Household chores } \\
\hline $\begin{array}{ll}0 & (12) \\
0 & (9)\end{array}$ & $\begin{array}{l}108 \\
180\end{array}$ & $\begin{array}{l}12 \\
11\end{array}$ & $\begin{array}{l}117 \\
175\end{array}$ & $\begin{array}{l}14 \\
11\end{array}$ & $\begin{array}{l}126 \\
206\end{array}$ & $\begin{array}{l}12 \\
11\end{array}$ & $\begin{array}{l}119 \\
204\end{array}$ & $\begin{array}{l}13 \\
13\end{array}$ & $\begin{array}{l}112 \\
240\end{array}$ & $\begin{array}{l}17 \\
23\end{array}$ \\
\hline
\end{tabular}

chores amongst the males whereas an increase was indicated in the females particularly during the final week of fasting. Representative daily activity patterns during the experimental period are presented in Fig. 1.

Fluid balance values are illustrated in Fig. 3. Total daily fluid intake in the form of fluid ingested and urine output showed large individual variations throughout the experimental period. Deviations of weekly means during fasting from the pre-fasting control means did not exceed $150 \mathrm{ml}$ for both variables. Samples of $24 \mathrm{~h}$ urine volume collected during the post-fasting period averaged 985 (SE 167) $\mathrm{ml}$ for the subjects examined. 


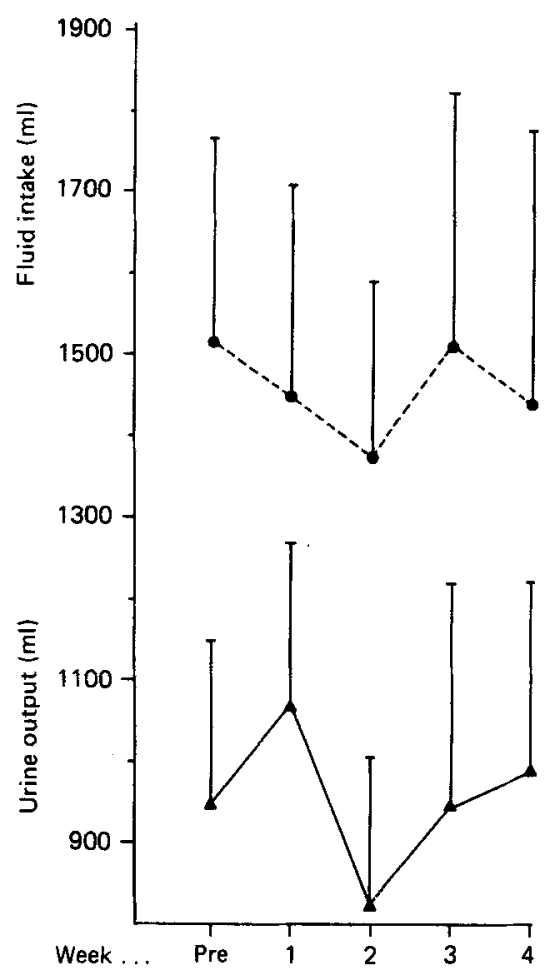

Fig. 3. Mean fluid intake $(\boldsymbol{-}-\mathbf{O}, \mathrm{ml})$ and total urine output $(\mathbf{\Lambda}-\mathbf{A}, \mathrm{ml})$ for $24 \mathrm{~h}$ in the pre-fasting control period (Pre) and in weeks $1-4$ of fasting in males $(n 10)$. Points are means with their standard errors represented by vertical bars.

\section{DISCUSSION}

Estimates of energy intake during normal feeding and activity are in agreement with suggested daily dietary intake for Malaysian populations of similar age, sex and body size with a light activity level (World Health Organization, 1973). Therefore in the non-fasting condition, the subjects would be in a state of metabolic equilibrium thereby maintaining a relatively constant body-weight. The male subjects reduced total food intake by a relatively constant amount throughout the fasting month. This was accompanied by a small decrease in body mass in terms of weight, body fat as assessed by skinfold thickness and muscle mass as assessed by muscle girth. The females experienced a decrease in body mass of greater magnitude than the males but their reduction in energy intake was less and more erratic compared with their male counterparts. In accordance with local custom, the onus of meal preparation for breaking fast at 19.00 hours and before commencing fast at 04.00 hours is associated with a high level of physical activity involving only the womenfolk. Activity information of the subjects presented in Fig. 1 and Table 3 is in agreement with this tradition. This practice may have resulted in a greater energy expenditure in the females compared with the males. Our findings negate the common local belief that Moslems tend to overcompensate in terms of food intake during the fasting month. The pattern of a net decline in energy intake prevails and is sufficient to result in weight loss in all the subjects at the end of the month of Ramadan.

The decline in resting RER seen in the present study indicates that fat assumed a greater role as substrate for energy production during fasting. Dietary records did not reveal an increase in the fat content of meals consumed whereas the findings showed a decline in body 
fat as assessed by skinfold thickness especially in the female group where the largest decline in RER occurred. Therefore the change in RER reflects increased mobilization of body fat. A decrease in RER during minor energy deprivation has been reported by others (Taylor et al. (1954).

Previous studies have shown that a reduced energy intake results in a lowered rate of $\mathrm{O}_{2}$ consumption (Bray, 1983) which appears to be independent of weight loss (Keys et al. 1950) and has been thought to serve as a metabolic adaptation to fasting (Young \& Landsberg, 1980). The present subjects showed a slight decrease in $\dot{V}_{\mathrm{O}_{\mathbf{2}}}$ throughout the fasting months. Possible reasons for this observation include a reduction in sympathetic activity associated with fasting (Young \& Landsberg, 1980). A lessened metabolic stimulatory effect due to attenuation of the specific dynamic action effect (Passmore \& Ritchie, 1957 ) is another possibility since a lapse of about $6 \mathrm{~h}$ would have occurred from meal time to gas collection time during Ramadan whereas only a $3 \mathrm{~h}$ interval was involved for the non-fasting control sessions due to the difference in breakfast time (Fig. 1).

The decrease in resting cardiac frequency maintained throughout the fasting month in the male subjects is believed to be caused by the Ramadan regimen and not attributable to habituation to experimental protocol. However, the heart rate of the female group was not similarly affected. A decline in cardiac frequency may be related to the effects of an altered mental state or decreased metabolic rate mediated by reduced sympathetic activity. Analysis of activity diaries submitted have shown that the time spent in religious activity by the males during the fasting month far exceeds that by the females. Furthermore, between $20.00-21.00$ hours in the evening, the male subjects would perform special Ramadan prayers while their female counterparts were engaged in domestic chores (Fig. 1).

It is therefore probable that increased religious dedication during the month of Ramadan results in an altered mental state which tends to lower metabolic rate and cardiac frequency.

Considerable individual variations in habits of fluid intake and urine output are apparent from the present findings. However, the general pattern emerging from the experimental means indicates the absence of marked changes in intake and output volumes as a result of the fasting regimen (Fig. 3). Present findings indicate that typical fluid exchange relations for the sedentary Malaysian male in ambient temperatures of $28 \pm 2^{\circ}$ with $80 \%$ relative humidity would be as follows: total fluid intake in the form of fluid ingested 1.4 litres/d, total urine output 0.9 litres/d. Additional sources of fluid input in the form of preformed water in food may approach 0.8 litres/d (Muntwyler, 1968), thus resulting in a total fluid input of 2.2 litres $/ \mathrm{d}$. Therefore, total evaporative loss would approximate $1.3 \mathrm{litres} / \mathrm{d}$, the difference between total fluid input $(2.2$ litres/d) and total urine output $(0.9$ litres/d). According to formulas and values presented by Weisberg (1962) and Kuno (1956), about two-thirds of evaporative loss may be attributed to insensible water loss and the remainder to thermal sweat loss. The fluid balance status of male Sudanese Moslems residing in a dry $32^{\circ}$ climate during the month of Ramadan were examined by Mustafa et al. (1978). The Sudanese fluid turnover rates were more than double that of our Malaysians and a marked drop in fluid intake occurred during the fasting period while urine output volumes remained unchanged, thereby resulting in a negative fluid balance. Estimates of evaporative water loss were about 2.8 litres/d. A smaller body size and higher environmental humidity in the Malaysian situation could have resulted in the relatively lower rates of total evaporative water loss indicated in the present study. Since the intake and urine output volumes during the fasting and non-fasting control periods were approximately the same, it can be assumed that our subjects were not in a state of negative fluid balance during the month of Ramadan. It can also be concluded that fluid balance shifts would not have contributed towards changes in body-weight.

Although available evidence generally indicates that the circadian cortisol and adrenaline 
rhythms are relatively resistant to environmental synchronizers (Fiorica et al. 1968; Weitzman. 1976; Akerstedt \& Levi, 1978), there remains the possibility that changes in meal frequency and sleep-activity cycles over a prolonged period, as in the month of Ramadan, may have effects on specific endogenous biological rhythms which may have subsequently altered some of the variables examined in the present study.

The authors are grateful to the subjects who volunteered for this study, the technical staff of the Physiology Department, and the University of Malaya for financial support.

\section{REFERENCES}

Akerstedt. T. \& Levi, L. (1978). European Journal of Clinical Investigation 8, 57-58.

Bray. G. A. (1983). Medicine and Science in Sports and Exercise 15, 32-40.

Consolazio. C. F.. Johnson. R. E. \& Pecora, L. J. (1963). Physiological Measurements of Metabolic Functions in Man. pp. 5-11. New York: McGraw-Hill.

Fiorica, V., Higgins, E. A., lampietro, P. F., Lategola, M. T. \& Davis, A. W. (1968). Journal of Applied Physiology 24. $167-176$.

Food and Agriculture Organization (1972). Food Composition Table for Use in East Asia. Rome: FAO.

Gumaa. K. A.. Mustafa, K. Y., Mahmoud, N. A. \& Gader, A. M. A. (1978). British Journal of Nutrition 40, 573-581.

Hodder, M. T. (1985). The Complete Asian Health and Diet Plan. Singapore: Times Book International.

Keys, A. J., Brozek, A., Mickelsen, O. \& Taylor, H. L. (1950). The Biology of Human Starvation, vols. 1-2. Minneapolis: University of Minnesota Press.

Kuno, Y. (1956). Human Perspiration. Springield: Charles, C. Thomas.

Muntwyler. E. (1968). Water and Electrolyte Metabolism and Acid-Base Balance. Saint Louis: C. V. Mosby.

Mustafa, K. Y., Mahmoud, N. A., Gumaa, K. A. \& Gader, A. M. A. (1978). British Journal of Nutrition 40 , 583-589.

National University of Singapore (1983). Composition of Foods Commonly Used in Singapore. Singapore: NUS.

Parnell. R. W. (1954). American Journal of Physical Anthropology 12, 209-239.

Passmore, R. \& Ritchie, F. J. (1957). British Journal of Nutrition 11, 79-85.

Taylor, H. L., Henschel, A., Mickelsen, O. \& Keys, A. (1954). Journal of Applied Physiology 6, 613-623.

Weisberg. H. F. (1962). Water, Electrolyte, and Acid-Base Balance. Baltimore: Williams and Wilkins.

Weitzman. E. D. (1976). Annual Review of Medicine 27, 225-243.

World Health Organization (1973). Working Table of Suggested Daily Dietary Intakes for West Malaysia. Technical Report Series no. 522. Geneva: WHO.

Young, J. B. \& Landsberg, L. (1980). Journal of Clinical Investigation 65, 1086-1094. 